\title{
XỬ TRÍ RÒ NỘI MẠCH SAU ĐIỀU TRI PHÌNH ĐỘNG MẠCH CHỦ BỤNG DƯớI THẬN BẰNG CAN THIỆP NỘI MẠCH
}

\author{
Nguyễn Văn Quảng ${ }^{*}$, Duoong Đinh Bảo*, Phạm Minh Ánh*
}

\section{TÓM TÁ́T}

Có 68 BN EVAR, tuổi trung bình là 73,6 \pm 3,1 ; nam giới 52 trường hợp $(\mathrm{TH})(76,47 \%)$. Có $19 \mathrm{TH}(27,9 \%)$ rò được phát hiện ngay lúc mổ (6 $\mathrm{TH}$ rò loại $\mathrm{IA}, 2 \mathrm{TH}$ loại $\mathrm{IB}, 8 \mathrm{TH}$ loại $\mathrm{II}, 3 \mathrm{TH}$ loại III). Có $3 \mathrm{TH}$ loại IA và $3 \mathrm{TH}$ loại III điều trị bằng nong bóng hiệu quả, 3TH loại IA đặt thêm ống ghép đoạn cổ gần, 2TH loại IB đặt thêm ống ghép đoạn cổ xa. Có 3 TH $(4,41 \%)$ can thiệp lại: $1 \mathrm{TH}$ rò loại IA đặt thêm ống ghép đoạn cổ gần, 1TH loại IB được đặt thêm ống ghép đoạn cổ xa, $1 \mathrm{TH}$ rò loại $\mathrm{II}$ có tăng kích thước phình làm tắc bằng thả coil thành công, các trường hợp còn lại ổn định, không có vỡ phình, không có tử vong liên quan túi phình. Rò nội mạch là biến chứng xảy ra với tần xuất thường gặp sau $E V A R$ và có thể điều trị hiệu quả bằng can thiệp nội mạch (nong bằng bóng, đặt thêm ống ghép nội mạch, làm tắc mạch).

Tù̀ khóa: Điều trị phình động mạch chủ bụng bằng can thiệp nội mạch, rò nội mạch

\section{SUMMARY}

\section{MANAGEMENT ENDOLEAK AFTER ENDOVASCULAR ANEURYSM REPAIR}

There were 68 EVAR procedures with mean age $73.6 \pm 3.1 ; 76.47 \%$ were male. Nineteen cases $(27.9 \%)$ of endoleak were detected intraoperative ( 6 cases of type IA, 2 cases of type IB, 8 cases of type II, 3 cases of type III). There were 3 cases of type IA and 3 cases of type III treated effectively with balloon dilation, 3 cases of type IA were treated by insertion of aortic cuff, 2 cases of type IB were inserted an extension stent graft. There were 3 cases $(4.41 \%)$ needed reintervention: 1 case of type IA with aortic cuff, 1 case of type IB with an extension stent graft, 1 case of type II with aneurysm size enlargement with coils embolization. The remaining cases were stable (no aneurysm rupture, no aneurysm related mortality). Endoleak is a common complication after EVAR and can be treated effectively by interventions (balloon dilatation, aortic cuff, extension stent graft, embolization).

Key words: Endovascular aneurysm repair (EVAR), endoleak

\section{I. ĐẠT VẤN ĐỀ}

Ở Mỹ, vỡ phình động mạch chủ bụng là một trong 10 nguyên nhân hàng đầu gây tử vong ở người trên 55 tuổi. Nguy cơ vỡ liên quan trực tiếp đến kích thước túi phình. Các túi phình có kích thước từ $5-6 \mathrm{~cm}$ có nguy cơ vỡ hàng năm từ 5 $10 \%$. Chỉ định phẫu thuật mở khi túi phình có kích thước từ $5-5.5 \mathrm{~cm}$. Tuy nhiên nguy cơ biến chứng, tử vong cho phẫu thuật mở từ $1-7 \%$. Gần đây, can thiệp nội mạch là phương pháp điều trị được chọn lựa với tỷ lệ biến chứng và tử vong 30 ngày thấp hơn, thời gian nằm viện và hồi sức ngắn hơn [2], [6], [10].

Tuy nhiên, điều trị nội mạch cũng tồn tại các biến chứng, đó là huyết khối ống ghép, gấp khúc và di lệch ống ghép, thuyên tắc mạch nuôi tạng hoặc chi, bóc tách động mạch chủ, và biến chứng thường gặp nhất là rò nội mạch.

Một số trường hợp rò nội mạch có thể làm tăng kích thước túi phình và dần đến vỡ phình gây tử vong cho bệnh nhân. Do đó, cần phát hiện kịp thời và có biện pháp điều trị thích hợp rò nội mạch nhằm giảm nguy cơ vỡ phình và tử vong cho bệnh nhân

\footnotetext{
* Khoa Phẫu thuật Mạch máu Bệnh viện Chơ Rã̃y Ngưòi chịu trách nhiệm khoa hoc: ThS. Nguyễn Văn Quảng Ngày nhận bài: 01/05/2018 - Ngày Cho Phép Đăng: 20/05/2018

Phản Biện Khoa học: GS.TS. Bùi Đưc Phú PGS.TS. Đặng Ngọc Hùng
} 
Nghiên cứu này nhằm khảo sát tỷ lệ rò nội mạch, các phương pháp và kết quả điều trị rò nội mạch sau điều trị phình động mạch chủ bụng dưới thận bằng can thiệp nội mạch.

\section{II. ĐỐI TƯợNG VÀ PHƯƠNG PHÁP NGHIÊN CÚUU}

Tiền cứu, mô tả các trường hợp rò nội mạch trong 68 bệnh nhân phình động mạch chủ bụng dưới thận được điều trị bằng can thiệp nội mạch tại khoa Phẫu thuật Mạch máu bệnh viện Chợ Rẫy từ tháng 05/2012 đến tháng $12 / 2017$ với thời gian theo dõi từ 6 tháng đến 60 tháng.

Rò nội mạch được phát hiện trong lúc mổ qua chụp động mạch chủ chậu số hoá xoá nền kiểm tra ngay sau khi bung ống ghép hoặc qua chụp điện toán cắt lớp động mạch chủ chậu trong quá trình theo dõi tại thời điểm sau can thiệp $1,3,6$, 12 tháng và hàng năm sau đó.

Các phương pháp điều trị rò nội mạch được sử dụng bao gồm nong bóng, đặt thêm ống ghép nội mạch đoạn cổ gần (aortic cuff) cho rò loại IA, đặt thêm ống ghép nội mạch đoạn cổ xa (extension stent graft) cho rò loại $\mathrm{IB}$, làm thuyên tắc mạch bằng coils qua can thiệp từ đường động mạch (transarterial embolization with coils) cho rò loại II, đặt thêm ống ghép nội mạch đoạn khúc nối cho rò loại III.

Rò nội mạch loại II được theo dõi định kỳ theo lịch, chỉ định can thiệp lại khi có tăng kích thước túi phình trên $5 \mathrm{~mm}$ hoặc rò tồn tại trên 6 tháng sau EVAR.

\section{KẾT QUẢ}

Chúng tôi đã thực hiện EVAR cho 68 bệnh nhân, tuổi trung bình là $73,6 \pm 3,1$; nam giới chiếm 52 trường hợp $(76,47 \%)$ với các yếu tố nguy cơ và bệnh kết hợp được mô tả ở bảng sau (Bảng 1)
Bảng 3.1. Đặc điểm chung bệnh nhân nhóm nghiên cứu

\begin{tabular}{|l|c|c|}
\hline \multicolumn{1}{|c|}{ Đặc điểm } & $\begin{array}{c}\text { Số bệnh nhân } \\
\mathrm{n}=68\end{array}$ & Tỷ lệ (\%) \\
\hline Tuổi trung bình & $73,6 \pm 3,1$ & \\
\hline Giới nam & 52 & $76,47 \%$ \\
\hline Tăng huyết áp & 16 & $23,52 \%$ \\
\hline Hút thuốc lá & 37 & $54,41 \%$ \\
\hline Rối loạn mỡ máu & 38 & $55,88 \%$ \\
\hline Đái tháo đường & 3 & $4,41 \%$ \\
\hline Bệnh mạch vành & 31 & 45,58 \\
\hline Hẹp động mạch cảnh & 9 & $13,23 \%$ \\
\hline $\begin{array}{l}\text { Bệnh phổi tắc nghẽn } \\
\text { mạn tính }\end{array}$ & 4 & $5,88 \%$ \\
\hline Bệnh thận mạn tính & 2 & $2,94 \%$ \\
\hline
\end{tabular}

Có 19 trường hợp $(27,9 \%)$ rò nội mạch được phát hiện ngay lúc mổ sau khi bung ống ghép nội mạch, bao gồm 6 trường hợp rò loại $\mathrm{IA}, 2$ trường hợp rò loại $\mathrm{IB}, 8$ trường hợp rò loại $\mathrm{II}, 3$ trường hợp rò loại III. Có 3 trường hợp rò loại $\mathrm{IA}$ và 3 trường hợp rò loại III được xử lý hiệu quả bằng nong bóng, 3 trường hợp rò loại IA được đặt thêm ống ghép đoạn cổ gần, 2 trường hợp rò loại IB được đặt thêm ống ghép đoạn cổ xa (Bảng 2). Chụp kiểm tra các trường hợp đặt thêm ống ghép này đều hết rò, không có rò tái phát trong quá trình theo dõi. Các trường hợp rò loại II được theo dõi định kỳ bằng chụp điện toán cắt lớp động mạch chủ chậu.

Bảng 3.2. Rò ống ghép nội mạch sớm và phương pháp điều trị

\begin{tabular}{|l|c|c|c|c|}
\hline Phân loại & $\begin{array}{c}\text { Nong bóng } \\
\text { thành công }\end{array}$ & $\begin{array}{c}\text { Đặt thêm } \\
\text { ông ghép }\end{array}$ & $\begin{array}{c}\text { Theo } \\
\text { dõi }\end{array}$ & $\begin{array}{c}\text { Tổng } \\
\text { cộng }\end{array}$ \\
\hline Loại IA & $3 / 6$ & $3 / 6$ & 0 & 6 \\
\hline Loại IB & 0 & $2 / 2$ & 0 & 2 \\
\hline Loại II & 0 & 0 & 8 & 8 \\
\hline Loại III & $3 / 3$ & 0 & 0 & 3 \\
\hline Tổng cộng & 6 & 5 & 8 & 19 \\
\hline
\end{tabular}


Trong quá trình theo dõi từ 6 đến 60 tháng có 3 trường hợp (4,41\%) can thiệp lại (Bảng 3 ) bao gồm 1 trường hợp rò loại IA được đặt thêm ống ghép đoạn cổ gần (aortic cuff), 1 trường hợp rò loại IB được đặt thêm ống ghép đoạn cổ xa (extension stent graft), 1 trường hợp rò loại II có tăng kích thước phình $10 \mathrm{~mm}$ (nguồn gốc rò từ nhánh động mạch thắt lưng chậu) được làm tắc bằng thả coils. Cả 3 trường hợp can thiệp lại này đều thành công về mặt kỹ thuật và chụp kiểm tra hết rò. Các trường hợp còn lại ổn định, không có vỡ phình, không có tử vong liên quan túi phình.

Như vậy, chúng tôi có tổng cộng 21/68 trường hợp rò nội mạch chiếm tỷ lệ 30,8\% (19 trường

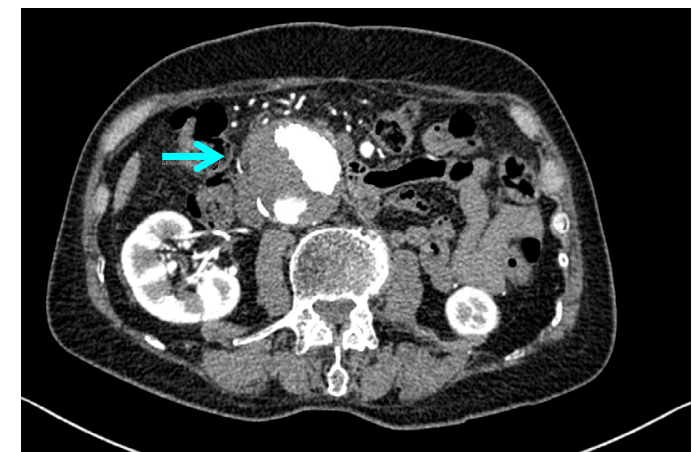

Hình 3.1. Rò loại IA

Nguồn tùu MSCT bệnh nhân Lê Văn T. hợp phát hiện trong lúc mổ, 2 trường hợp phát hiện trong quá trình theo dõi)

Bảng 3.3. Rò ống ghép nội mạch muộn và kết quả can thiệp lại

\begin{tabular}{|l|c|c|c|}
\hline Phân loại & $\begin{array}{c}\text { Đặt thêm } \\
\text { ông ghép }\end{array}$ & $\begin{array}{c}\text { Làm tắc } \\
\text { mạch }\end{array}$ & $\begin{array}{c}\text { Tổng } \\
\text { cộng }\end{array}$ \\
\hline Loại IA & 1 & 0 & 1 \\
\hline Loại IB & 1 & 0 & 1 \\
\hline Loại II & 0 & 1 & 1 \\
\hline Tổng cộng & 2 & 1 & 3 \\
\hline
\end{tabular}

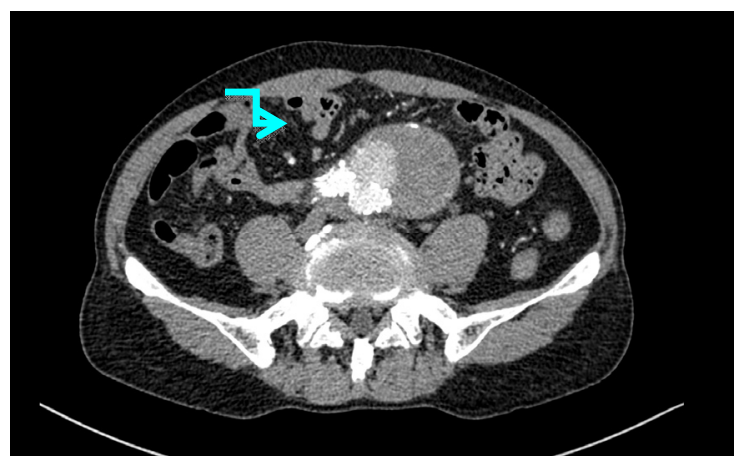

Hình 3.2. Rò loại $I B$

Nguồn tù MSCT bệnh nhân Nguyễn Tấn L

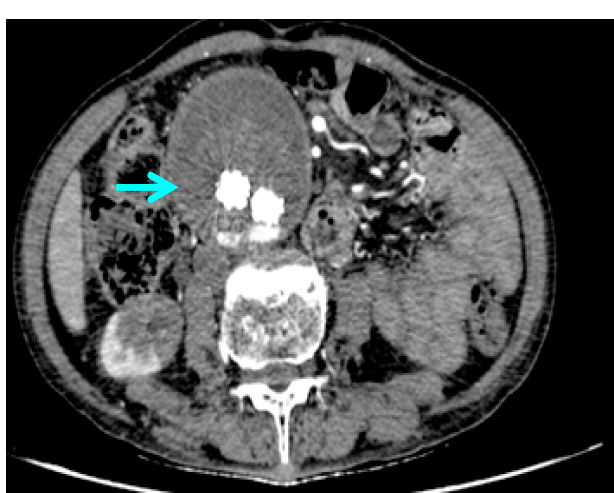

A

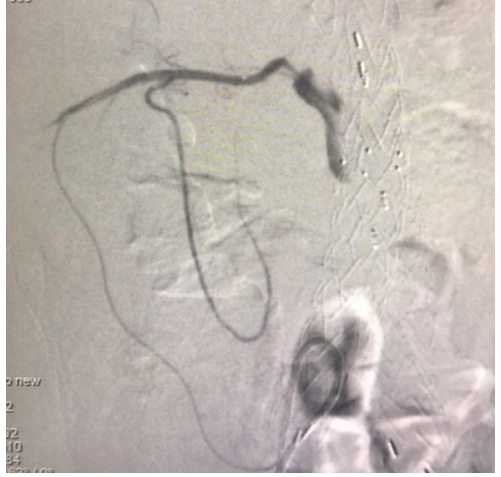

$\mathrm{B}$

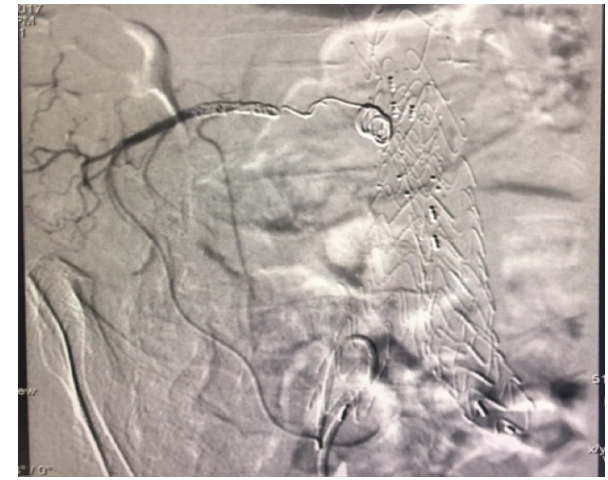

$\mathrm{C}$

Hình 3.3. Rò nội mạch loại II: Nguồn tù̀ MSCT bệnh nhân Nguyễn Minh T

A: Hình ảnh rò trên phim MSCT truớc can thiệp lại,

B: Hình ảnh rò qua chụp mạch máu xoá nền truớc can thiệp lại,

$$
\text { C: Sau thả coil làm tắc mạch }
$$




\section{BÀN LUẬN}

Rò nội mạch được xác định khi vẫn còn dòng máu chảy vào túi phình sau can thiệp đặt ống ghép nội mạch điều trị phình động mạch chủ. Rò có thể xuất hiện trong vòng 30 ngày sau can thiệp, gọi là rò sớm hay nguyên phát, rò thứ phát hay muộn là các trường hợp rò xuất hiện sau đó. Ngoài ra người ta còn phân loại rò có liên quan ống ghép và không liên quan ống ghép. Tần suất rò ống ghép thay đổi từ $10 \%-50 \%[7]$.

Phân loại thường được sử dụng nhất là phân loại dựa trên nguồn gốc xuất phát của dòng máu vào túi phình. Theo đó, rò nội mạch được phân thành 5 loại như sau [5]:

- Loại I: Rò từ cổ gần (IA) hoặc cổ xa của túi phình (IB)

- Loại II: Rò từ các nhánh bên động mạch chủ vào túi phình như: động mạch thắt lưng, động mạch mạc treo tràng dưới, động mạch chậu trong

- Loại III: Rò từ chỗ hở giữa các khúc nối của ống ghép

- Loại IV: Rò từ thân ống ghép

- Loại V (endotension): Tăng áp lực bên trong túi phình làm tăng kích thước phình, không thấy hình ảnh rò trên các phương tiện chẩn đoán hình ảnh
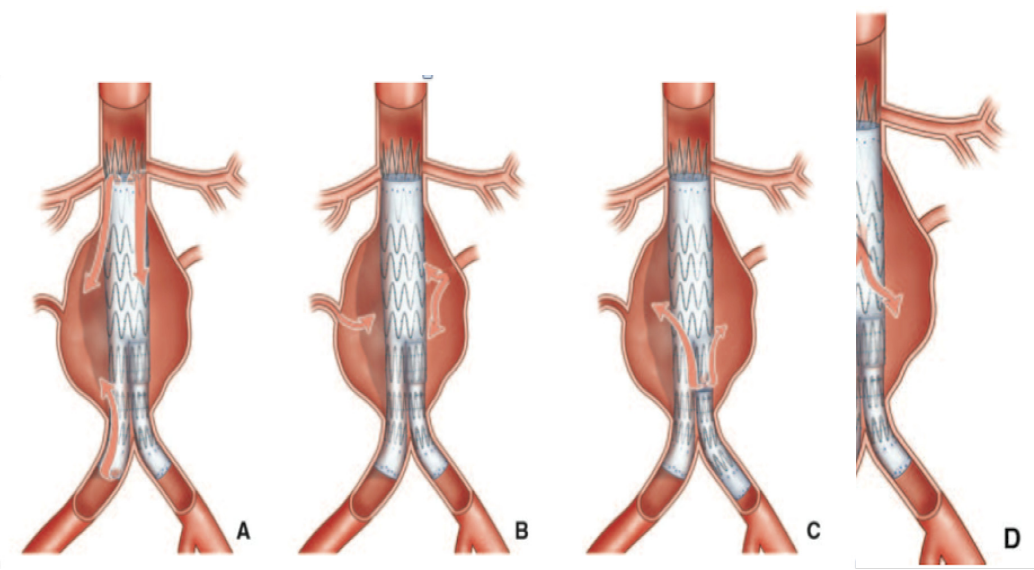

Hình 4. Các loại rò nội mạch (A: loại I, B: loại II, C: loại III, D: loại IV) Nguồn tù̀ EMC - Technique chirurgical [1]

Tần xuất rò nội mạch loại I sau can thiệp nội mạch điều trị phình động mạch chủ bụng dưới thận dao động từ $0-10 \%$, rò loại II từ $10-25 \%$ [5]. Tỷ lệ rò loại I trong nghiên cứu chúng tôi là $14,7 \%$, tỷ lệ rò loại II là $11,8 \%$. Kết quả này cũng tương tự các nghiên cứu của các tác giả khác [3], [9], [10].

Về chỉ định can thiệp, rò ống ghép nội mạch loại I và loại III có sự liên quan trực tiếp giữa áp lực trong túi phình và tuần hoàn hệ thống nên cần được xử trí ngay nhằm tránh nguy cơ vỡ phình. Rò ống ghép nội mạch loại II xuất phát từ các nhánh bên của động mạch chủ đỗ vào túi phình, theo nhiều nghiên cứu cho thấy loại rò này có khả năng tự khỏi từ 30-90\% [5], do đó có thể theo dõi mà chưa cần can thiệp ngay.

Một số công trình nghiên cứu cho thấy chỉ định can thiệp lại cho rò loại II khi kích thước túi phình tăng trên $5 \mathrm{~mm}$ trong quá trình theo dõi hoặc rò tồn lại trên 6 tháng đến 1 năm [4]. Trong nghiên cứu của chúng tôi có 8 trường hợp rò loại II được phát hiện và theo dõi, có một trường hợp tăng kích thước túi phình $10 \mathrm{~mm}$ và bênh nhân có đau bụng sau can thiệp 1 năm. Trường hợp này 
được can thiệp lại: qua chụp động mạch chủ chậu số hoá xoá nền chúng tôi xác định được nguồn gốc gây rò từ nhánh động mạch thắt lưng chậu bên phải, bệnh nhân được thả coil làm tắc thành công. Chụp kiểm tra sau can thiệp lại hết rò và bệnh nhân giảm đau.

Các nghiên cứu trên thế giới cho thấy có nhiều biện pháp xử trí rò nội mạch, bao gồm nong bóng, đặt thêm stent động mạch chủ cho đoạn cổ gần, đặt thêm ống ghép nội mạch đoạn cổ gần (aortic cuff), đặt thêm ống ghép chỗ khúc nối, đặt thêm ống ghép nội mạch đoạn cổ xa, làm thuyên tắc mạch qua đường đường động mạch hoặc xuyên thắt lưng, mổ nội soi thắt các nhánh mạch, hoặc chuyển mổ hở... [4], [7], [8]

Nghiên cứu của chúng tôi không có trường hợp phải chuyển mổ mở, tất cả các trường hợp rò được xử trí thành công bằng can thiệp nội mạch ngay trong thì đầu hoặc ở lần can thiệp lại cho các trường hợp rò muộn phát hiện trong quá trình theo dõi hoặc rò loại II tồn tại, có tăng kích thước túi phình.

Điều trị thành công rò nội mạch bằng can thiệp nội mạch góp phần duy trì tính ưu việt của EVAR là ít xâm lấn, giảm tử vong và biến chứng trong điều trị phình động mạch chủ bụng dưới thận, đặt biệt ở các bệnh nhân có nguy cơ phẫu thuật cao do lớn tuổi, có nhiều bệnh kết hợp.

\section{KẾT LUẬN}

Rò nội mạch là biến chứng xảy ra với tần xuất thường gặp sau EVAR và có thể điều trị hiệu quả bằng can thiệp nội mạch (nong bằng bóng, đặt thêm ống ghép nội mạch, làm tắc mạch). Cần theo dõi định kỳ để phát hiện sớm và xử trí kịp thời nhằm tránh biến chứng vỡ phình. Cần có nghiên cứu tiếp theo với cỡ mẫu lớn hơn để đánh giá tốt hơn về biến chứng này.

\section{Tài liệu tham khảo}

1. Becquemin J.P, Cochennec F, Marzelle J (2006), "Chirurgie endovasculaire des anévrismes de l'aorte abdominale", Techniques chirurgicales - Chirurgie vasculaire, Elsevier Masson SAS.
2. De Bruin JL, Baas AF, Buth J, et al (2010), "Long-term outcome of open or endovascular repair of abdominal aortic aneurysm". $N$ Engl J Med; 362(20): 1881-1889.

3. El Batti S, Cochennec F, Roudot-Thoraval F, Becquemin JP (2013), "Type II endoleaks after endovascular repair of abdominal aortic aneurysm are not always a benign condition", $J$ Vasc Surg.; 57(5): 1291-1297.

4. Elliot L. Chaikof, Ronald L. Dalman Mark K. Eskandari Benjamin M. Jackson (2017), “The Society for Vascular Surgery practice guidelines on the care of patients with an abdominal aortic aneurysm", Journal of vascular surgery, volume 67, Number 1.

5. Frank J. Veith, Richard A. Baum, Takao Ohki (2002), "Nature and significance of endoleaks and endotension: Summary of opinions expressed at an international conference”, $\mathrm{J}$ Vasc Surg; 35: 1029-35.

6. Lederle FA, Freischlag JA, Kyriakides TC et al (2012), "Long-termcomparison of endovascular and open repair of abdominal aortic aneurysm", N Engl J Med; 367(21): 1988-1997.

7. Moll FL, Powell JT, Fraedrich G et al (2011), "Management of abdominal aortic aneurysms clinical practice guidelines of the European society for vascular surgery", Eur J Vasc Endovasc Surg; 41 (Suppl 1): S1-S58.

8. Peter L. Faries, Hadley Cadot, Gautam Agarwal, K. Craig Kent, Larry H. Hollier, and Michael L. Marin (2003) "Management of endoleak after endovascular aneurysm repair: Cuffs, coils, and conversion", J Vasc Surg; 37: 1155-61.

9. Sidloff DA, Gokani V, Stather PW, Choke E, Bown MJ, Sayers RD (2014), "Type II endoleak: conservative management is a safe strategy". Eur J Vasc Endovasc Surg; 48(4): 391-399.

10. Stather PW, Sidloff D, Dattani N, Choke E, Bown MJ, Sayers RD (2013), "Systematic revie and meta-analysis of the early and late outcomes of open and endovascular repair of abdominal aortic aneurysm”, Br J Surg; 100(7): 863-872. 